Proceedings

\title{
Determining the Thermal Diffusivity of the Ground from an Experimental Geothermal Borehole ${ }^{\dagger}$
}

\author{
M. P. Castro-García ${ }^{1, *}$, G. Marcos-Robredo ${ }^{1}$, M. A. Rey-Ronco ${ }^{1}$ and T. Alonso-Sánchez ${ }^{2}$ \\ 1 Department of Energy, University of Oviedo, 33004 Oviedo, Mieres, Spain; \\ marcosgerman@uniovi.es (G.M.-R.); rey@uniovi.es (M.A.R.-R.) \\ 2 Department of Mining Exploitation and Prospecting, University of Oviedo, 33004 Oviedo, Mieres, Spain; \\ tjalonso@uniovi.es \\ * Correspondence: castromaria@uniovi.es; Tel.: +34-985-10-43-19 \\ + Presented at the 2nd International Research Conference on Sustainable Energy, Engineering, Materials and \\ Environment (IRCSEEME), Mieres, Spain, 25-27 September 2018.
}

Published: 2 November 2018

\begin{abstract}
This article presents a method for determining in-situ ground apparent thermal diffusivity based on heat transfer by conduction.
\end{abstract}

Keywords: thermal diffusivity; borehole; mathematical; model

\section{Introduction}

Thermal diffusivity of the ground is fundamental parameter in the design of shallow geothermal plants, and the determination of this has been the subject of many research projects and scientific publications.

The thermal diffusivity of soils and rocks can be obtained from laboratory experiments which however, often yield unsatisfactory results since they usually deal with a small size sample in spite of heterogeneities of the real field [1,2]. Furthermore, in the case of soils, it is difficult to take undisturbed samples as preserved as the natural condition of the materials.

In most geothermal applications, it is necessary to know the apparent thermal diffusivity of the ground materials traversed by geothermal borehole rather than thermal diffusivity of the different rocks.

Previous studies have established calculation methods for the on-site determination of apparent thermal diffusivity in grounds containing a borehole [3]. The thermal diffusivity results obtained are in line with the results found in the literature, but can be improved by: (1) modeling the temperature variation over a period of time that is greater than one year, and (2) comparing the variations in the annual frequencies of the ambient temperature and the underground temperature.

The present study presents a calculation method for on-site determination of apparent underground thermal diffusivity, based on a conductive heat transfer model, via long series of recordings of ambient temperature and of underground temperature at different depths.

\section{Mathematical Model}

The annual temperature variation caused by seasonal changes has been analyzed, confirming that the variation in the temperature records over time and at depth $x$ follows a periodic function $T(x, t)$ defined by equation [1].

$$
T(x, t)=T_{m}+A_{0} \cdot e^{-x \cdot \sqrt{\frac{\pi}{P \cdot \alpha}}} \cdot \sin \left(\omega \cdot t+\emptyset-x \cdot \sqrt{\frac{\pi}{P \cdot \alpha}}\right)
$$


where:

- $T(x, t)$ is the periodic function of the variation in temperature at depth $x$ over time.

- $T_{m}$ is the average ambient temperature over one year, (at $x=0$ and $t=0$ ).

- $A_{0}$ is the maximum amplitude of the ambient temperature in the period under consideration, and

- $\omega$ is the angular frequency of the periodic variation that satisfies $\omega=2 \cdot \pi / P$, where:

- $\mathrm{P}$ is the period of the study, in this case one year $(31,536,000 \mathrm{~s})$.

- $\quad x$ is the position of the temperature sensor with respect to the surface of the ground.

- $\varnothing$ is the time difference between the theoretical model $(t=0)$ and the experiment period $(t \neq 0)$.

- $\varphi_{x}$ is the time difference in the ambient temperature found between data gathered at one point in time, and the onset of the ideal sine curve, and is equal to $\varphi_{x}=x \cdot \sqrt{\frac{\pi}{P \cdot \alpha}}$.

- $A_{x}=A_{0} \cdot e^{-x \cdot \sqrt{\frac{\pi}{P \cdot \alpha}}}$ is the maximum amplitude of the temperature at depth $x$ in the period under study. This value is dependent on the amplitude of the ambient temperature, and varies with the depth under consideration and with the apparent thermal diffusivity between the surface and said depth.

Under these conditions, and for the purpose of determining thermal diffusivity $\alpha$, it is necessary to measure $T(x, t)$, i.e., the variation in the ambient temperature and in the temperature at different depths over a period of at least one year.

\section{Experimentation}

A borehole was drilled for the purpose of geothermal research. The 125-mm diameter, 48-mdeep borehole was drilled by roto-percussion with a down-the-hole hammer. The water table level in the ground at the time of drilling was $20 \mathrm{~m}$ (from surface).

Coaxial geothermal pipes were chosen due to the small diameter of the borehole. This tubing consists of an outer tube with a diameter of $50 \mathrm{~mm}$, and a concentric inner tube with a diameter of 25 $\mathrm{mm}$, connected at their lower end in such a way that the liquid that travels down the ring section can travel back up.

Geophysical testing was carried out on the borehole in order to determine the lithologies that had been drilled through, revealing various levels of limestones, clays and dolomites.

The borehole was set up so that its internal temperature can be monitored. To do so, commercial TMCX-HD temperature sensors were placed on the external wall of the outer geothermal tube, at 1.67 $\mathrm{m}, 3.86 \mathrm{~m}$, and $6.08 \mathrm{~m}$ from the surface of ground. These sensors measure within a range of -40 to 50 ${ }^{\circ} \mathrm{C}$, and are accuracy down to $\pm 0.25^{\circ} \mathrm{C}$ from 0 to $50{ }^{\circ} \mathrm{C}$. The TMCx-HD temperature sensors were connected to a HOBO model U-12-006 data logger, manufactured by the Onset Computer Corporation.

\section{Results}

The apparent thermal diffusivity $\alpha$ between the surface and a given depth $x$ was determined using the set of values $T(x, t)$ measured over the course of one year inside the bore hole. The mathematical adjustments to Equation (1) have made it possible to determine the apparent thermal diffusivity $\alpha$ at different depths, the results of which have been summarized in Table 1.

Table 1. Results for apparent thermal diffusivity obtained using the sinusoidal mathematical model.

\begin{tabular}{ccc}
\hline Profundidad, $\boldsymbol{x}[\mathrm{m}]$ & $\mathbf{R}^{\mathbf{2}}$ & Apparent Thermal Diffusivity $\boldsymbol{\alpha}\left[\mathrm{m}^{2} / \mathrm{s}\right]$ \\
\hline 1.67 & 0.9594 & $1.275 \times 10^{-6}$ \\
3.86 & 0.9681 & $1.446 \times 10^{-6}$ \\
6.08 & 0.9854 & $1.566 \times 10^{-6}$ \\
\hline
\end{tabular}




\section{Conclusions}

The present study presents a calculation method for on-site determination of apparent underground thermal diffusivity, based on a conductive heat transfer model, via long series of recordings of ambient temperature and of underground temperature at different depths.

A research borehole was drilled and sensors were placed to record the temperature at depths of $1.67 \mathrm{~m}, 3.68 \mathrm{~m}$ and $6.08 \mathrm{~m}$, in addition to a sensor placed at the surface to determine the daily and seasonal variations in ambient temperature throughout the recording period (greater than one year).

The borehole passes through limestone, marly limestone and dolomite, and the phreatic level is located at $20 \mathrm{~m}$.

The proposed mathematical model has been shown to be valid for determining the apparent thermal diffusivity in a borehole that is not influenced by the phreatic level, as the results obtained are in line with those found in the literature.

\section{References}

1. Busby, J.; Lewis, M.; Reeves, H.; Lawley, R. Initial Geological Considerations before Installing Ground Source Heat Pump Systems. Q. J. Eng. Geol. Hydrogeol. 2009, 42, 295-306, doi:10.1144/1470-9236/08-092. Available online: https://www.bgs.ac.uk/research/energy/docs/final_paper.pdf (accessed on 11 June 2018).

2. Hellström, G.; Sanner, B. Software for dimensioning of deep boreholes for heat extraction. In Proceedings of the Calorstock Conference, Helsinki, Finland, 22-25 August 1994.

3. Arias-Penas, D.; Castro-García, M.P.; Rey-Ronco, M.A.; Alonso Sánchez, T.J. Determining the Thermal Diffusivity of the Ground Based on Subsoil Temperatures. Preliminary Results of an Experimental Geothermalborehole Study Q-THERMIE-UNIOVI. Geothermics 2015, 51, 35-42, doi:10.1016/j.geothermics.2014.10.006. Available online: https://www.sciencedirect.com/science/article/pii/S0375650514001266 (accessed on 11 June 2018).

(C) 2018 by the authors. Licensee MDPI, Basel, Switzerland. This article is an open access article distributed under the terms and conditions of the Creative Commons Attribution (CC BY) license (http://creativecommons.org/licenses/by/4.0/). 